\section{FORMAS DEL ESTADO DE DERECHO Y DELIMITACIÓN DEL DERECHO AL BUEN GOBIERNO'}

\author{
Mercedes Galán Juárez \\ (Universidad Rey Juan Carlos)
}

\begin{abstract}
This article analyzes the suitable legal and political framework for citizens to exercise their right to good government. After describing the social condition of human beings that leads them to come together and bind themselves to a political organization through a social contract, the different historical forms of the Rule of Law are analyzed up to the Constitutional Rule of Law. The current Constitutionalism combines the principles of legality and legitimacy. This means that the validity of a regulation from a strictly formal perspective is not sufficient; its content must also respect the values, principles and fundamental rights established in the Constitution. The Spanish Constitution of 1978 emphasizes the significance of the individual and individual dignity (Section 10.1) and the instrumental role of the Public Administration as a political organization which shall serve the general interests in a spirit of objectivity (Section 103.1). This is the appropriate legal framework for achieving not only the efficiency and effectiveness of the government, but also the quality of its services.

Furthermore, the government has ethical commitments to its citizens, which entails carrying out policies which are consistent with these commitments and avoiding policies which are not. This legal, political and ethical exposition makes it possible to understand good government in all its complexity.
\end{abstract}

KEY WORDS: Citizen; good government; social contract; Rule of law; human dignity; human rights; public interests; government; individual; democracy.

\section{DeReChO AL BUEN GOBIERNO: DELIMITACIONES PREVIAS}

Si partimos de la formulación derecho al buen gobierno, vemos que aparece el término derecho (con minúscula). Como han reiterado gran parte de los teóricos del derecho, el Derecho es un término ambiguo, es vago y tiene varias acepciones, lo que dificulta su conceptualización ${ }^{2}$. Una de esas acepciones es la de derecho en sentido subjetivo, que significa el poder o facultad que tiene su titular para exigir a otro una determinada conducta ${ }^{3}$. Pero, ¿en virtud de qué tiene uno ese poder de exigir?, ¿quién le da esa facultad?, ¿se lo otorga uno mismo?, ¿le corresponde a otra persona reconocer ese poder?
FORMS OF THE STATE OF LAW AND DEMARCATION OF THE RIGHT TO A GOOD GOVERNANCE

RESUMEN: Este artículo analiza cuál es el marco político y jurídico adecuado para que los ciudadanos hagan efectivo su derecho al buen gobierno. Después de exponer la condición social del hombre que le lleva a agruparse con otros hombres y a vincularse a una organización política por medio de un pacto o contrato social, se analizan las distintas formas históricas del Estado de Derecho hasta llegar al Estado Constitucional de Derecho. El Constitucionalismo actual aúna el principio de legalidad y legitimidad, lo que significa que no basta con que una norma sea válida desde un punto de vista estrictamente formal sino que se requiere que su contenido respete los valores, principios y derechos fundamentales establecidos en la Constitución. Por su parte, la Constitución Española de 1978, al resaltar la centralidad de la persona y su dignidad (art. 10.1) y destacar el valor instrumental de la Administración pública como organización política al servicio objetivo de los intereses generales (art. 103.1), establece el marco jurídico adecuado para conseguir no sólo la eficiencia y la eficacia de la gestión pública, sino la calidad de sus servicios.

Asimismo, el gobierno tiene unos compromisos morales con los ciudadanos, lo que conlleva realizar políticas coherentes con dichos compromisos y prevenir y perseguir las que no lo sean. Este planteamiento jurídico, político y ético hace posible entender el buen gobierno en toda su complejidad.

PALABRAS CLAVE: Ciudadano; buen gobierno; pacto social; Estado de Derecho; dignidad humana; derechos humanos; intereses generales; gobierno; persona; democracia.

La respuesta es negativa porque "estos derechos subjetivos sólo pueden ser puestos en vigor y sólo pueden ser hechos cumplir por organizaciones que tomen decisiones colectivamente vinculantes. $Y$ a su vez, estas decisiones deben su carácter colectivamente vinculante a la forma jurídica de que están revestidas"4. Si no fuera así, si cada uno de nosotros tuviéramos la capacidad de delimitar lo que podemos o no podemos hacer jurídicamente y exigirlo en consecuencia a los demás, entonces se produciría un constante abuso del poder del más fuerte, una enorme inseguridad jurídica y, en consecuencia, un caos insalvable. Esto no tiene sentido ni en el plano de la lógica en el marco del discurso jurídico. 
Hay que señalar por tanto la necesaria correlación que existe entre derecho subjetivo y derecho objetivo, y entre derecho y deber. ${ }^{5}$. Si se tiene un derecho es porque hay un Derecho que otorga o reconoce un derecho. Ese Derecho, entendido en sentido objetivo como conjunto de normas, está a su vez elaborado por quien detenta la competencia legislativa en un poder legítimo.

Si se entiende el derecho al buen gobierno como un derecho en el sentido expuesto, éste otorga a su titular el poder de exigir a un tercero lo que la norma que le ha facultado prescribe ${ }^{6}$ y coloca a su vez al Estado en una posición de deber de cumplir esta prestación.

El repaso de nuestro ordenamiento jurídico permite constatar que en la Constitución no existe ninguna norma que exprese literalmente tal derecho si bien si se refiere al principio de buena administración de forma implícita cuando determina la manera de actuar de las administraciones públicas en los artículos 9.3, 31.2 y 103.1 de la Constitución Española. A su vez, la Ley 7/2007, de 12 de abril, del Estatuto Básico del Empleado Público, en su exposición de motivos afirma que "las administraciones y entidades públicas de todo tipo deben contar con los factores organizativos que les permitan satisfacer el derecho de los ciudadanos a una buena administración"7. El artículo 41 de la Carta de los derechos fundamentales de la Unión Europea, que lleva por título precisamente "el derecho a una buena administración", dispone:

1. Toda persona tiene derecho a que las instituciones y órganos de la Unión traten sus asuntos imparcial y equitativamente y dentro de un plazo razonable.

2. Este derecho incluye en particular:

- El derecho de toda persona a ser oída antes de que se tome en contra suya una medida individual que le afecte desfavorablemente.

- El derecho de toda persona a acceder al expediente que le afecte, dentro del respeto a los intereses legítimos de la confidencialidad y del secreto profesional y comercial.

- La obligación que incumbe a la Administración de motivar sus decisiones.

3. Toda persona tiene derecho a la reparación, por la Comunidad, de los daños causados por sus institucio- nes o sus agentes en el ejercicio de sus funciones, de conformidad con los principios generales comunes a los Derechos de los Estados miembros.

4. Toda persona podrá dirigirse a las instituciones de la Unión en una de las lenguas de los Tratados y deberá recibir una contestación en esa misma lengua"8.

"La buena administración se nos presenta, por tanto, como un nuevo principio rector de la actuación de las administraciones públicas y como un derecho fundamental (...). Como nuevo derecho (...) su novedad radica en el hecho de que logra integrar bajo un nuevo concepto un conjunto de subderechos ya existentes". Además, "como principio rector comporta la imposición a los poderes públicos de una conducta tendente a hacer realidad el contenido del principio (...) Como mandato se dirige al legislador y al resto de poderes públicos"9. Igualmente la Administración tiene el deber de servir con objetividad y eficacia a los intereses generales (art. 103.1 de la Constitución Española), lo cual otorga a la persona la posibilidad de exigir que lo público esté atendido de forma y manera que le permita realizarse, en su dimensión de libertad solidaria, como persona humana desde diferentes dimensiones ${ }^{10}$.

\section{EL BUEN GOBIERNO O BUENA ADMINISTRACIÓN}

La segunda parte de la expresión de la que partimos es la de buen gobierno o buena administración. Hablar de derecho al buen gobierno parece una redundancia, como ocurre con otros términos en nuestro ordenamiento, por ejemplo, cuando en el Código Civil se hace referencia a la diligencia de un buen padre de familia. Sin embargo, en otros casos no se habla de tener derecho a una buena educación o a un derecho a la huelga efectiva o una asociación eficaz.

Aparte de ser una redundancia per se, puede también resultar en cierta medida superfluo hablar de buen gobierno desde la perspectiva de nuestros Estados sociales y democráticos consolidados, que cuentan con una división de poderes consolidada, con el reconocimiento de derechos fundamentales, y con los principios de legalidad y legitimidad, entre otros. Además, parece que no tuviéramos gobiernos o que los que tenemos no pudieran ser considerados como tales al no ser "buen gobierno". Nadie a estas alturas puede 
afirmar ni una cosa ni la otra y los hechos demuestran que se han logrado unos altos niveles de convivencia democrática a pesar de nuestra corta historia constitucional democrática y que el gobierno -en el sentido más amplio del término y sea quien fuere el partido político gobernante- funciona. En todo caso, tiene una connotación positiva innegable y es aceptado comúnmente como la máxima aspiración de un gobierno. Es más, no se hablar tanto de un mal gobierno, sino de un no gobierno o, como diría Alejandro Nieto, de un desgobierno ${ }^{11}$. ¿Por qué aspiramos a un buen gobierno?

Porque no nos conformamos con tener un gobierno solamente, ni unos dirigentes políticos que nos gobiernen. ¡Será por dirigentes políticos! Nunca hemos tenido tantos a nivel internacional, europeo, nacional, regional o local. Lo que se está reclamando es que nos gobiernen bien. Esto exige un elemento cualitativo diferenciador. Pero, ¿qué significa esto?

Significa muchas cosas pero una de las más importantes es que nos gobiernen de acuerdo con las reglas de la ética pública. También significa que los servicios públicos sean eficaces, eficientes y que se sometan al derecho y que tengan en cuenta al ciudadano como centro de su actividad y que sirvan a los intereses generales ${ }^{12}$.

De nuevo es obligada la referencia al artículo 103.1 de la Constitución Española cuando se refiere a que "la Administración sirve con objetividad a los intereses generales" -obsérvese que no dice que debería servir-. Cuando esto ocurre, ¿es simplemente Administración o buena Administración?

Aunque la Administración tiene que operar según el referido mandato constitucional, incluso aunque de hecho actúe en consonancia con él, el "principio de buena administración responde a las concepciones más recientes del derecho administrativo, caracterizadas por el intento de superar la visión estrictamente formal que legitima la Administración para el mero cumplimiento neutral y objetivo de la norma que le otorga las potestades de actuación y, por otro lado, por la voluntad de situar al ciudadano en el centro de la preocupación de las normas que ordenan la actividad administrativa". De hecho, el modelo anterior de administración jerarquizada ya no es válido como tampoco lo es que limite su actuación al cumplimiento de unas nor- mas que definen minuciosamente cuál es el interés general que hay que alcanzar. "Administrar bien requiere tener en cuenta aspectos relativos a la organización interna, a la forma de adoptar las resoluciones generales e individuales, a los criterios para determinar los servicios que hay que prestar y a las maneras de actuar para conseguir que estos servicios lleguen a los ciudadanos de forma regular y con la mayor calidad posible"13.

Una vez presentado el ideal de buen gobierno y el buen gobierno como ideal político, se hace necesario preguntarse cómo se ha ido articulando su contenido y cuáles son las razones que justifican su exigencia. Una respuesta adecuada pasa por hacer una reflexión conceptual e histórica de dos términos en torno a los cuales se construye la filosofía política moderna, que hunden sus raíces en la existencia misma del hombre y que explican hasta qué punto el proceso de socialización y politización son innatos en el ser humano. Se trata de los conceptos de estado de naturaleza y de contrato social.

\section{RAZONES HISTÓRICAS Y CONCEPTUALES QUE JUSTIFICAN LA NECESIDAD DE UN GOBIERNO, LA EXISTENCIA DEL ESTAdO Y LA EXIGENCIA DE BUEN GOBIERNO}

\section{El estado de naturaleza: presupuestos antropológicos}

¿Cuál es el fin último del hombre?, ¿en qué consiste nuestra naturaleza humana?, ¿es el hombre sociable por naturaleza?, ¿cómo se forma la sociedad política?

Estas preguntas han sido formuladas por los pensadores que han elaborado una teoría política desde la Antigüedad y han cobrado especial énfasis en la Modernidad. Sin embargo, sus respuestas no siempre han sido homogéneas, sobre todo cuando justifican las razones por las que se produce el paso del estado de naturaleza al de sociedad civil. No en vano se ha dicho que el concepto estado de naturaleza se sitúa en una encrucijada en la que confluyen la concepción del hombre como ser natural como sujeto moralizado, portador de derechos y de deberes, o como un ser de deseo con unos medios excepcionales (la razón, el lenguaje) nacidos de la historia (Rousseau) o inscritos en la constitución misma del hombre (Hobbes), de modo que haga falta el Derecho para regularlo ${ }^{14}$. 
La expresión estado de naturaleza puede tener dos dimensiones, una conceptual y otra histórica ${ }^{15}$. La primera permite entender el estado de naturaleza en el sentido más amplio, como la condición natural del hombre en cualquier momento y lugar $y$, por tanto, atemporal. Esta condición puede ser susceptible de ser interpretada en un doble sentido: por una parte, como "condición de guerra de todos contra todos, en el cual uno está gobernado por su propia razón, no existiendo nada, de lo que pueda hacer uso, que no le sirva de instrumento para proteger su vida contra sus enemigos". Ahora bien, esta condición trasciende cualquier momento histórico concreto puesto que "nunca existió un tiempo en que los hombres particulares se hallaran en una situación de guerra de uno contra otro, en todas las épocas, los reyes y personas revestidas con autoridad soberana, celosos de su independencia, se hallan en continua enemistad"16. Rousseau tampoco sitúa en el tiempo la salida del estado de naturaleza, más bien se refiere a que hay "un punto en el que los obstáculos que dañan a su conservación [la del hombre] en el estado de naturaleza logran superar mediante la resistencia, la fuerza que cada individuo puede emplear para mantenerse en ese estado"17. Para Kant, "El estado no-jurídico (...) es el estado natural. (...) A él no se opone el estado social, sino el estado civil de una sociedad sometida a la justicia distributiva; porque el estado de naturaleza también puede hacer sociedades legítimas (por ejemplo, la conyugal, la familiar, la doméstica en general, y otras)"18.

Aristóteles entiende que "la ciudad es una de las cosas naturales y que el hombre es, por naturaleza, un animal cívico. Y el enemigo de la sociedad ciudadana es, por naturaleza, y no por casualidad, o bien un ser inferior 0 más que un hombre. (...) La ciudad es por naturaleza y es anterior a cada uno. Porque si cada individuo, por separado, no es autosuficiente, se encontrará con las demás partes, en función a su conjunto. Y el que no puede vivir en sociedad, o no necesita nada para su propia suficiencia, no es miembro de la ciudad, sino como una bestia o como un dios". La sociabilidad innata al hombre se proyectaria en el Estado, que pasa a ser un hecho natural, lo que hace que el hombre que viva alejado de la sociedad sea un ser degradado o un ser superior a la especie humana. La naturaleza arrastra instintivamente a todos los hombres a la asociación política. De ahí que el Estado no sea un artefacto sino que supone la materialización del desarrollo de la naturaleza, que destina a los hombres a la vida política, satisfaciendo en ella toda su humanidad ${ }^{19}$. Aunque alejado en el tiempo, Calhoun se refiere también a la exigencia de un gobierno para que el hombre pueda asumir plenamente el estado social hasta tal punto que "en ninguna era o pais se ha observado ninguna sociedad o comunidad civilizada o en estado salvaje sin un gobierno de cualquier tipo". Junto a esta constatación empírica, señala también que la integración del hombre en sociedad sería la que permitiría "alcanzar el desarrollo completo de sus capacidades morales e intelectuales, o elevarse en la escala de la existencia por encima del nivel de la creación bruta"20.

De todas estas contribuciones se deduce que no se concibe la posibilidad de que el hombre viva aislado por muy primaria que sea su existencia. Es más, su propia supervivencia fisica y moral, estaría en juego puesto que es en relación con los demás hombres en donde el hombre encuentra su razón de ser y su identidad. Desde un punto de vista jurídico, y enlazando con la reflexión inicial en torno a la teoría del Derecho, ya se señalaba cómo para el ejercicio de un derecho subjetivo se necesita su reconocimiento por parte de una norma que otorga el Estado.

Que el hombre sea un ser social por naturaleza es una realidad aceptada mayoritariamente ${ }^{21}$ en el sentido de que resulta difícil asimilar que el hombre tenga una inclinación natural al aislamiento de sus semejantes. Es más, no faltan quienes consideran que "ese supuesto estado de naturaleza, es una pura ficción". De hecho "el estado primitivo del hombre fue un estado de unión y de sociedad; que el estado social es el más conforme a la naturaleza del hombre, y por consiguiente, que el hombre ha nacido sociable". Se justifica diciendo que "ninguna persona sensata creería jamás que para ser virtuoso, es preciso renunciar a la beneficencia, a la generosidad y a las otras virtudes que suponen un estado de sociedad, puesto que no pueden desarrollarse sino en nuestras relaciones con nuestros semejantes". El que vive como un salvaje "tampoco ve el ejemplo de muchas virtudes que no ejerce ni puede ejercer". De ahí que se reconozca que, "independientemente de todos los bienes palpables y materiales que nos siguen de vivir en sociedad, hay en el fondo de nuestro ser, como lo acredita la experiencia, una cierta inclinación a unirnos con otros hombres" y llama "sentimiento de sociabilidad" al placer que se nos sigue de esta inclinación cuando la satisfacemos ${ }^{22}$. 
Es a partir de la época moderna, en resuelta oposición a la tesis que siguen la doctrina aristotélica, cuando se extiende la idea de que "la comunidad política no es un hecho de naturaleza sino un artificio que hombres libres e independientes se dan para satisfacer sus propias necesidades (...). La humanidad del hombre no depende esencialmente de su relación con los otros en la construcción de un orden justo"23. Desde esta perspectiva, el estado de naturaleza tendría la dimensión histórica aludida, ya que se referiria a la posición del hombre, del individuo antes del contrato social por el que se somete a los dictados del gobierno, tal y como se configura en el Estado Moderno.

El concepto de estado de naturaleza que se maneja en esta época "responde a la necesidad de invertir las relaciones de determinación: éstas irán desde el individuo hacia la sociedad que éste crea por contrato, y no ya desde la sociedad hacia el individuo que ésta constituiría como hombre en el pleno sentido de la palabra". Como consecuencia "el hombre es el creador -y no el efecto- de sus propias condiciones de existencia; que en la condición en la que la naturaleza lo ha colocado, e independientemente de los compromisos artificiales y contractuales que suscribe luego por propia iniciativa, el hombre existe como individuo dotado de necesidades, de deseos y de derechos"24. Ese protagonismo del hombre hace que el Estado y la sociedad pasen a un segundo plano y que en el discurso jurídico acentúe más el lenguaje de los derechos que el los deberes, siendo sobre éstos últimos sobre los que la mayor parte de los textos legales habian descansado hasta el momento ${ }^{25}$.

La posición que el individuo ocupa en el nuevo contexto histórico es coherente con la ideología ilustrada que envuelve el pensamiento moderno y con el individualismo imperante en los albores del siglo XVIII cuando se reclaman los derechos que le corresponden al hombre por su propia naturaleza y que son anteriores a cualquier pacto social y su consiguiente reconocimiento por parte del Estado ${ }^{26}$. Serán derechos naturales y universales, entendidos como libertades que los individuos tienen frente al poder, que debe garantizarlos.

Esa nueva concepción de los derechos y el papel central del hombre, no habría sido posible si éste no hubiera tomado conciencia de su individualidad y de la necesidad de pensar por sí mismo sin tener que estar a la sombra de la conducción ajena. Los hombres al salir de la "minoría de edad" en la que han estado por "falta de resolución y valor", "difundirán en torno suyo el espíritu de una estimación racional del propio valor y de la vocación a pensar por sí mismo". Para llevar a cabo "esta ilustración tan sólo se requiere libertad y (...) el hacer uso público de la razón en todos los terrenos". Esta nueva actitud del hombre ilustrado "repercute sobre la mentalidad del hombre (merced a lo cual éste va haciéndose cada vez más apto para la libertad de actuar) y finalmente acaba por tener un efecto retroactivo hasta sobre los principios de gobierno, el cual incluso termina por encontrar conveniente tratar al hombre, quien ahora es algo más que una máquina, conforme a su dignidad"27. Por tanto, el ejercicio de la libertad y de entendimiento propio del hombre ha tenido un efecto no sólo hacia él mismo, que se siente libre de la dependencia ajena, sino que la honda expansiva llega hasta su vida en la comunidad política, que no será la de mero receptor de los dictados ajenos -aunque también tiene que obedecerlos- sino la de partícipe de los mismos. La transformación que supone el modo de pensar ilustrado puede servir para entender el trasfondo del buen gobierno, que caracteriza a aquel que, como hemos visto, se realiza teniendo en cuenta la dignidad de la persona y sus derechos y que sirve a los intereses generales. El ciudadano estará en condiciones de reclamar un buen gobierno cuando sea consciente de su propia identidad como ciudadano. Al ejercer su capacidad de pensar por sí mismo estará en condiciones de expresar sus exigencias jurídicas y cumplir sus deberes, lo que repercutirá también en su consideración de buen ciudadano.

En un sentido parecido a Kant se expresa Humboldt cuando analiza el fin último del hombre, al que sitúa en el centro de su teoría política y sobre el que proyecta los rasgos del idealismo. Reclama la máxima libertad para el hombre porque sólo así podrá "desarrollarse por sí mismo y en su propia individualidad" poniendo como restricciones a sus "necesidades e inclinaciones" "los límites de su fuerza y su derecho"28. El reconocimiento de la libertad innata en el ser humano también es un rasgo de la concepción antropológica de Rousseau cuando categóricamente afirma que "el hombre ha nacido libre y en todas partes se encuentra encadenado" y el rol que le corresponde al hombre, sometido a la primera ley de la naturaleza humana, es "velar por

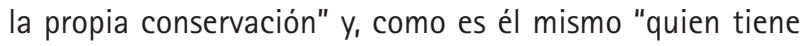
que juzgar cuáles son los medios más apropiados para su conservación, se convierte en su propio amo"29 
Si conjugamos los elementos que hasta ahora venimos exponiendo, vemos que más allá de que exista un concepto abstracto y atemporal del estado de naturaleza, a partir de un momento determinado de la historia, la filosofía política se construye en torno a este concepto, junto con los de contrato social y Estado, lo cual no quiere decir que fueran reflexiones ajenas al pensamiento político anterior. La especulación sobre lo político ha sido una constante en la historia del pensamiento ${ }^{30}$, y especialmente las formas en que se han llevado a cabo las relaciones entre los gobernantes y gobernados. El hecho de que sean las teorias contractualistas del pensamiento político moderno las que hayan centrado la mayor parte de nuestra atención, se justifica porque en ellas podemos encontrar las razones para una teoría del buen gobierno. De momento podemos concluir que no existe una conexión directa e inmediata entre estado de naturaleza y buen gobierno -excepto en la teoría política de Aristóteles-, porque si bien la naturaleza social del hombre le lleva a vivir en sociedad de tal manera que pudiera satisfacer al máximo sus intereses y lograra superar la guerra de todos contra todos, eso sólo será posible mediante un acto que se concreta en el pacto social. Es decir, la idea básica de la civilización jurídica moderna, invirtiendo la concepción aristotélica, es que el Derecho o el Estado no son lo natural, sino la ausencia de Derecho y el Estado de naturaleza ${ }^{31}$. Éste se caracteriza, por tanto, por ser un gobierno de los hombres en el que confluirán todos los intereses individuales y en el que hay una falta de leyes generales a las que se tenga que someter en primer lugar quien tiene el poder de dictarlas. En definitiva, parece que la clásica pregunta sobre si es mejor el gobierno de las leyes o el gobierno de los hombres encuentra, por nuestra parte, respuesta en la primera parte de su formulación, ya que es en éste marco en donde se articularán los intereses contrapuestos de los hombres. Además, la exigencia de generalidad y constancia de la ley, tal y como defiende Aristóteles, aporta alguno de los ingredientes necesarios para establecer los presupuestos de un buen gobierno ${ }^{32}$.

Si volvemos a la cuestión de la naturaleza del hombre, podemos preguntarnos con Calhoun "¿Cuál es la constitución de nuestra naturaleza, que, al mismo tiempo que impulsa al hombre a asociarse con los de su género, hace imposible que la sociedad exista sin gobierno?". Su respuesta es que "[el hombre] está constituido de tal modo que sus afecciones directas o individuales son más fuertes que sus sentimientos comprensivos o sociales" y ello "conduce, necesariamente, al conflicto entre los individuos", que será resuelto por el poder controlador del gobierno. De ahí que "el hombre está constituido de tal forma que el gobierno es necesario para la existencia de la sociedad, y la sociedad para su existencia y perfección de sus facultades" ${ }^{\prime 3}$. Esta interdependencia entre el hombre, la sociedad y el gobierno serán esenciales para entender el siguiente rótulo de nuestro trabajo.

\section{SOCIEDAD CIVIL, GOBIERNO Y ESTAdO}

El hombre ha asumido su inclinación natural a vivir en sociedad a pesar de que el apego a sus intereses particulares confluya con los de los demás. Originariamente su vida se desenvuelve en grupos sociales como son la familia o la amistad y sus relaciones sociales se van ampliando a medida que va desarrollando otras facetas de su vida (profesional, política o cultural).

Podemos preguntarnos si en esta fase de consolidada socialización -entendida como mera convivencia entre los hombres- existe algún tipo de organización por encima de la propia sociedad o si esta agrupación tiene entidad en si misma independientemente de un orden externo. En definitiva, detrás de esta reflexión está la clásica delimitación conceptual de la sociedad civil y el Estado. Hay quien considera que la sociedad civil equivale a la "comunidad políticamente organizada en un Estado", identificando por tanto ambos término ${ }^{34}$. Creemos que quienes hacen ésta identificación se centran en el punto de partida, estado de naturaleza, más que en el de destino, Estado. Es más, conciben esa situación originaria de naturaleza como aquella en la que los individuos carecen de vínculos sociales y políticos, es decir, que no tienen ningún tipo de organización social y política. La situación que más se acercaría a esta interpretación del estado de naturaleza sería la de Hobbes cuando describe al individuo solitario en guerra permanente con todos los demás. Si, en efecto, se sitúa al hombre aislado y se llama estado de naturaleza a esta situación, y si se concibe la socialización del hombre como una segunda etapa de su desarrollo, entonces se puede entender que el Estado como organización política estaría al final de este proceso.

La teoria de Marx y Engels centra su atención en el estado natural del hombre, pero no aislado sino que en él mismo 
se ubica la sociedad civil. No falta quien ve un paralelismo entre la definición que hace esta teoría de la sociedad civil y el carácter específico del estado de naturaleza hobbesiano de guerra de todos contra todos: "Toda la sociedad civil es precisamente esta guerra [del hombre contra el hombre], uno contra otro, de todos los individuos, aislados uno de otro ahora sólo por su individualidad, y es el movimiento general, desenfrenado, de las potencias elementales de la vida liberadas de las cadenas de los privilegios" ${ }^{25}$.

Coincidimos en la delimitación de la sociedad civil en relación con otro término, previo o posterior a su formación. Sin embargo, es en el Estado en donde encontramos el elemento de referencia adecuado para su completa comprensión. La sociedad civil sería aquella organización pre-estatal en la que se engloban las relaciones de familia, profesionales o de amistad, y que el Estado no regularía, puesto que sus competencias se centran en aquellos aspectos de la sociedad civil que deben ser exigidos coactivamente para garantizar el ejercicio de los derechos de todos. Desde esta perspectiva, nos centraríamos en enfatizar el carácter social del hombre, proyectado en la sociedad civil, y en la posterior dinámica política, concretada en el Estado. Son nuestras necesidades las que nos Ilevan a crear la sociedad -diriamos, a vivir en sociedad-y nuestros conflictos los que nos conducen al Estado ${ }^{36}$. Además, la constatación de derechos naturales que, a pesar de que le pertenecen al ser humano, no le son ajenos al Estado en la medida que tiene que velar por su protección implica que la sociedad civil y el Estado no son compartimentos estancos. El mero hecho de que se hable de tres acepciones del término sociedad civil, cronológica, axiológica y mixta ${ }^{37}$, pone de manifiesto hasta qué punto existe esa conexión entre ésta y el Estado.

Más allá de las disquisiciones doctrinales respecto a que la sociedad civil sea precondición del Estado, su antítesis o represente su disolución y fin, la sociedad civil es una entidad diferente al Estado, concebido ya como sociedad política, pero que no está al margen de él ni al Estado le resulta ajena.

La sociedad no puede vivir como si el Estado no existiera porque, tal y como hemos explicado al referirnos al estado de naturaleza, los conflictos sociales son inevitables ${ }^{38}$ y la supervivencia de la sociedad estaría en juego ${ }^{39}$. Las exigencias políticas de los ciudadanos, entre las que se encuentra la de buen gobierno, no tendrían sentido si no existiera una entidad política -el Estado- a la que poder dirigirlas y cumplirlas. "El Estado es necesario como poder de sanción, como poder de organización y como poder de ejecución porque los derechos han de imponerse, porque la comunidad jurídica necesita tanto de una fuerza estabilizadora de su identidad como de una administración organizada de justicia"40.

\section{Del Estado de Derecho al Estado Constitucional de Derecho}

Se ha resaltado la necesidad del Estado en relación al mantenimiento del orden en la sociedad. A continuación será preciso centrarse en el propio concepto de Estado para comprender su naturaleza y competencias de tal forma que nos permita delimitar sus fines. De ahí que se puedan plantear las siguientes preguntas: ¿La existencia del Estado responde a un momento determinado o es una realidad histórica?, ¿cómo se produce la transformación del Estado originario de Derecho al Estado actual de Constitucionalismo democrático?

Las respuestas a estas preguntas están condicionadas por lo que se entienda por Estado, una vez que se ha aclarado que es una entidad separada de la sociedad pero a la vez interdependiente. El Estado en sentido amplio es una forma jurídico política de organización social que tiene un poder soberano en un territorio. Si bien no debe confundirse la noción de Estado con la de gobierno, sin embargo una de las funciones del Estado es gobernar, entendiendo por tal dirigir o mandar con autoridad una colectividad política. Desde esta perspectiva, se puede afirmar que siempre ha existido Estado en cuanto que ha habido una organización política de la sociedad por muy primaria que ésta fuera. Por tanto, parece que no hay motivo para no encontrar una prolongación del Estado a lo largo del tiempo siempre y cuando se haya dado la idea de la unidad del poder en un determinado territorio aunque sea una sociedad fraccionada y policéntrica como la de los primeros siglos o en donde existe el poder personal de un hombre investido por deseo divino del mando sobre otros hombres ${ }^{41}$.

A pesar de que esta visión amplia del Estado pueda resultar válida en términos conceptuales, sin embargo no 
es suficiente para poder cumplir las expectativas sociales y políticas de los ciudadanos en un momento dado, que se situaría en torno a la época Moderna y que llega hasta nuestros días. Esta nueva época pone de manifiesto que el sentido del término "Estado" que se había utilizado hasta el momento ya no es de aplicación. De ahí que en adelante, cuando se hable de Estado, se haga para referirse únicamente a las formaciones politicas que nacen de la crisis de la sociedad medieval y no para los ordenamientos anteriores. "El Estado representa el paso de la época primitiva, dividida en salvaje y bárbara, a la época civil, donde 'civil' significa al mismo tiempo 'ciudadano' y 'civilizado'"42. Hasta tal punto se trata de un término que designa una realidad histórica concreta -moderna-, que al producirse tal asociación entre los términos Estado y moderno, su transposición a otras realidades históricas anteriores podría resultar artificial.

La configuración originaria del Estado moderno es el de una entidad al que los hombres le exigen el reconocimiento de las libertades que tenían antes del pacto o contrato por el que se habían vinculado a él. El impacto que tenga sobre el hombre este pacto social ha sido interpretado de forma distinta según los autores. Así, se ha afirmado que el hombre "mediante la participación activa siempre pide mayor protección al Estado y mediante la exigencia de protección refuerza aquel Estado del que quisiera adueñarse y que en cambio se vuelve su amo"43. Para otros, el contrato social supone para el hombre perder "su libertad natural y un derecho ilimitado a todo lo que le apetece y puede alcanzar" mientras que "lo que gana es la libertad civil y la propiedad de todo lo que posee" ${ }^{\text {"4 }}$. Para Kant "el contrato social (...) no se considera un hecho histórico, sino que se entiende como una idea racional que consiste en obligar a cualquier legislador a hacer sus leyes 'como si éstas hubieran surgido de la voluntad conjunta de todo el pueblo'"45.

Ahora bien, además de las diferentes razones expuestas, ¿existen otros motivos para entrar en ese estado "sociolegal", como diría Kant? Según este autor hay un "deber primordial e incondicionado"46 de organizar la sociedad conforme con el estado civil puesto que si no se hiciera, peligraria la seguridad de cada uno y sería una constante amenaza para los demás. En coherencia con estas razones se justificaría el fin del Estado que puede ser doble, según Humbold: o bien "proponerse fomentar la felicidad o simplemente evitar el mal (...). Si se limita al segundo fin, busca solamente la seguridad"47. Él rechaza el primero de los fines, puesto que el principio de que el gobierno se ocupe de la felicidad y del bienestar de la nación es el peor de los despotismos, de ahí que el Estado deba aspirar a garantizar la seguridad de los ciudadanos. En el trasfondo de esta aspiración está el papel central que ocupa el ideal de la formación del hombre. El hombre tiene que realizar un proceso de formación, que consiste en llegar a una armonía consigo mismo, proceso que sólo él mismo puede realizar ${ }^{48}$.

Una vez delimitado por qué es necesario entrar en un estado civil, hay que indagar con qué medios se cuenta para mantenerlo. El principal cauce es el Derecho, al que Kant confiere un valor regulador fundamental pero no como un fin en sí mismo sino como un medio para cumplir la naturaleza y vocación de los hombres ${ }^{49}$. De hecho, "una acción es conforme a derecho (...) cuando permite, o cuya máxima permite, a la libertad del arbitrio de cada uno coexistir con la libertad de todos según una ley universal"50.

Es este papel del Derecho el que servirá para aportar un atributo al originario concepto de Estado, que tendrá una cualidad adicional como Estado de Derecho. Ya no se trata de una organización cualquiera, sino aquella que sigue conservando el poder como rasgo característico de su condición política ${ }^{51}$, pero que está sometida al Derecho y que se autolimita a través de las siguientes condiciones: garantía de los derechos y libertades fundamentales de los ciudadanos ${ }^{52}$, imperio de la ley, entendido como expresión de la voluntad general, división de poderes y legalidad de la Administración ${ }^{53}$. La ley, por tanto, tiene preeminencia sobre la Administración, la Justicia y la Sociedad. Es un Estado asentado en el principio de legalidad. Por tanto, el énfasis recae en la idea de sometimiento al Derecho más que en la idea de Derecho, puesto que la existencia de normas no es un elemento definitorio de un Estado. De hecho, para que sea posible el mantenimiento del orden en la sociedad, desde las épocas más antiguas, ha sido necesario que hubiera normas que la regularan. Sin embargo, los que detentaban el poder y ejercian la responsabilidad política no estaban vinculados por las normas que ellos mismos hacían. De ahí que la configuración del Estado como Estado de Derecho aporta un elemento cualitativo diferenciador importante respecto a las formas anteriores de concebir la relación entre el Estado y los súbditos, que 
ahora pasarían a ser considerados como ciudadanos, no meros subordinados.

Tal y como se ha conceptualizado, el Estado de Derecho remite al plano del Derecho y no solamente al plano de la Moral, que es el otro gran orden normativo con el que el Derecho ha convivido tradicionalmente y al que sometian la validez de las normas. De ahí que el concepto de Estado de Derecho se vincule a una concepción positivista del Derecho, es decir, es el Derecho puesto por las autoridades delegadas para ello por el mismo ordenamiento jurídico. La validez de la norma no depende de su justicia o racionalidad, sino de su positividad. En este contexto, "el tema de la legitimidad ha tomado otra orientación, ya no la de los criterios axiológicos, sino la de las razones de la eficacia de la que deriva la legitimidad" 54 .

En la forma originaria del Estado de Derecho se sitúa al individuo frente al Estado, que es el que históricamente ha vulnerado sus derechos y frente a quien se le protege. Sin embargo, esa visión no reduce al Estado a un segundo plano ni limita su actuación a ser simplemente un ente pasivo que debe de abstenerse de vulnerar los derechos del hombre. El Estado moderno tiene valor por sí mismo como "sustancia ética", en la terminología de Hegel. Esto significa que "el principio de acción del Estado debe ser buscado en su propia necesidad de existencia, que es la condición misma de la existencia (... también de la libertad y del bienestar) de los individuos" 55 .

Éstas serán las coordenadas en las que se moverá el Estado en su incipiente configuración como Estado de Derecho y, en la medida en que ajuste a ella su actuación y objetivos, podrá decirse que será un "buen gobierno". Sin embargo, si bien estas condiciones son esenciales para asentar las bases de un buen gobierno, no son suficientes para su realización plena, tal y como hoy lo concebimos. Entendemos que en esta fase del desarrollo de la forma del Estado de Derecho falta el compromiso de los gobernantes a favor de la vertebración social del Estado y del interés genera ${ }^{56} y_{\text {, }}$ sobre todo, la consideración del Estado no como un fin en sí mismo sino como un medio para el desarrollo individual y social del ser humano. El Estado no puede ejercer su poder solamente desde la ley. Además, el Estado no es "el único actor en la arena política. Importa articular correctamente este conjunto de actores con una distribución acertada de cometidos, de técnicas de organización y de contrapoderes. Importa la 'gobernanza' de esta diversidad de sujetos" ${ }^{17}$.

El Estado de Derecho fue transformándose sobre todo a lo largo del siglo XIX y principios del XX en un Estado liberaldemocrático de Derecho en el que progresivamente se fueron logrando la universalización de los derechos civiles y políticos previamente conquistados. $Y$ es en ese núcleo estable en el que se terminó injertando el Ilamado Estado social de Derecho ${ }^{58}$. Se ha señalado que fue $H$. Séller quien acuñó la expresión Estado Social como representativo de las nuevas funciones de los poderes públicos, que no se preocupan sólo por asegurar la libertad de los ciudadanos, sino también su situación económica, reconociendo ciertos derechos sociales ${ }^{59}$. En esta nueva forma del Estado de Derecho la sociedad no se sitúa enfrente del Estado sino a su lado, en la medida en que éste es su mejor aliado para la consecución de los fines sociales a los que va destinada su actividad. Es más, como materialización de la forma política social de Derecho que orienta la Constitución Española de 1978, ésta prescribe a los poderes públicos a través de su artículo 9.2 la obligación de "promover las condiciones para que la libertad y la igualdad del individuo y de los grupos en que se integra sean reales y efectivas; remover los obstáculos que impidan o dificulten su plenitud y facilitar la participación de todos los ciudadanos en la vida política, económica, social y cultural". En esta fase, se amplían los derechos y se garantizan la eficacia y efectividad de los derechos sociales, independientemente de quién sea el sujeto prestador ${ }^{60}$.

Por último, el Estado constitucional de Derecho se configura como una organización política sometida al Derecho pero no a cualquier Derecho, no a normas axiológicamente neutras, sino a aquellas que condensan los valores democráticos de libertad, igualdad, pluralismo político y justicia (art. 1 de la Constitución Española). Para ello se establece que hay una norma suprema, que es la Constitución, que no sólo es el criterio de legalidad de las normas, sino de legitimidad del sistema. Proclama el techo valorativo de todas las normas infraconstitucionales y los fines a los que tienen que dirigirse las actuaciones de los poderes públicos. La Constitución reconoce los derechos como derechos fundamentales, lo que representa un nuevo contenido de los derechos constitucionales. A partir de su reconocimiento constitucional, todo derecho tiene una dimensión subjetiva, que exige la no intromisión de los poderes públicos en unas esferas de libertad individuales, y otra objetiva, que conlleva la obligación 
de los poderes públicos de desarrollar una conducta activa en garantía de estos derechos. Por tanto, todo derecho fundamental es un derecho de libertad y un derecho de prestación ${ }^{61}$. Como veremos a continuación, éste último elemento será determinante para terminar de exponer las condiciones necesarias para la calificación de un buen gobierno.

\section{Conclusión: Estado de Derecho y buen gobierno}

Si tuviéramos que hacer una valoración del desarrollo de las formas del Estado de Derecho desde su configuración moderna hasta la actualidad, veriamos que el Estado Constitucional de Derecho representa la superación del Estado de Derecho legislativo y su rasgo más sobresaliente es la limitación y el control del poder ${ }^{62}$. En el nuevo contexto constitucional, las reclamaciones y expectativas de los grupos sociales se trasladan al Estado gobernante y administrador. Este elemento, junto con el que hemos enfatizado de posición del ciudadano en el centro de la preocupación política hasta el punto que la razón del ser del poder público está en promover el desarrollo de la dignidad de la persona, serán determinantes para la materialización del principio de buen gobierno. Además, la garantía de la vigencia de los derechos fundamentales no puede ceñirse a la posibilidad de su ejercicio por parte de los individuos, sino que tiene que ser asumida también por el Estado, lo que se traduce en la obligación positiva de contribuir a la efectividad de tales derechos y de los valores que representan ${ }^{63}$.

Sin embargo, a pesar del avance que ello representa, no significa que sea suficiente contar con un Estado Constitucional como única garantía de un buen gobierno. Es necesario además que, en el proceso de protección del ciudadano ante el poder político, se siga exigiendo al Estado la obligación positiva de buen gobierno. Ya no nos conformamos con un Estado que sea de Derecho, ni que sea liberal, ni que sea social, ni siquiera que sea democrático y constitucional, tiene que tener una calidad ética, que en el fondo no es ni más ni menos que ser lo que se espera de un Estado que aglutina tantos calificativos, entre los que está implícita su exigencia ética ${ }^{64}$. Pues bien, si un gobierno actúa teniendo

Recibido: 28 de enero de 2009

Aceptado: 14 de febrero de 2009 en cuenta los elementos que hemos señalado, los ciudadanos se sentirian representados, sus intereses estarían satisfechos y podrian ejercer el control político de su actividad. De lo contrario, reinarán las prácticas corruptas, el abuso de poder, la ineficiencia e ineficacia y la vulneración sistemática de los derechos fundamentales.

El artículo 103 de la Constitución Española del que partíamos, da una respuesta al para qué actúa la Administración -para garantizar el interés general-, y al cómo -con objetividad-. Los dos términos -objetividad e interés general- están vinculados y se complementan en la medida en que no es posible actuar parcialmente y servir al interés general, porque lo que se produciría como resultado sería actuar siguiendo los intereses particulares de quien detenta el poder ${ }^{65}$. Ahora bien, esa búsqueda del interés general no puede ser a cualquier precio. El precio lo señala el Derecho, puesto que la primera condición que se le pide a un Gobierno es que cumpla el Derecho, que a su vez le marca las pautas de su actuación: el sometimiento a los principios de eficacia, eficiencia, transparencia, etc., y que respete los valores del artículo 1 de la Constitución. Por tanto ese Derecho al que se somete el Estado también tiene que ser "buen Derecho", y bueno significa, desde un punto de vista jurídico, que tienda a la realización de su fin último, que es la realización de la Justicia. Además de estar sometido al Derecho, el gobierno tiene unos compromisos morales que conforman una ética pública y que también sirven de marco delimitador de su actuación.

Acorde con las delimitaciones morales, jurídicas, políticas e históricas que hemos realizado, podemos concluir que el buen gobierno aporta un elemento cualitativo a la acción del Estado, al calificar como tal aquel que tiene como centro de gravedad en la persona humana, su dignidad y sus derechos. A partir de esta idea capital vendrán todas las demás exigencias cuantitativas. La realidad demuestra todavía que el buen gobierno sigue siendo un desiderátum en la mayor parte de los Estados, hasta el punto que los líderes mundiales se han comprometido a alcanzar en el 2015 un programa llamado las Metas de Desarrollo del Milenio y Objetivos de Desarrollo del Mileno, entre los que se encuentran, la democracia, los derechos humanos y el buen gobierno ${ }^{66}$. 
1 Este artículo ha sido realizado en el marco del Proyecto de Investigación HUM2006-03669/FISO ("Una fundamentación de los derechos humanos desde la lógica del razonamiento jurídico").

2 Entre los numerosos autores que manifiestan el problema de la definición del Derecho están: Martínez Roldán, J., y Fernández Suárez, J. A.: Curso de Teoría del Derecho y Metodología jurídica, Ariel, Barcelona, 1994, pp. 14-57; Pérez Luño, A. E.: Teoría del Derecho. Una concepción de la experiencia jurídica, con la colaboración de C. Alarcón Cabrera, R. González Tablas y A. Ruiz de la Cuesta, Tecnos (6. edición), pp. 2745; Segura Ortega, M.: Manual de Teoría del Derecho, Editorial Centro de Estudios Ramón Areces, pp. 93100; Nino, C. S.: Introducción al Derecho, Ariel, pp. 11-16. J. Vara Martín recoge extractos de obras clásicas en las que aparecen diversas acepciones del término derecho. "Libres, buenos y justos: como miembros de un mismo cuerpo", Lecciones de Teoría del Derecho y del Derecho Natural, Tecnos, pp. 80-84.

$3 \mathrm{H}$. Kelsen ubica el tema de "El derecho subjetivo: tener derecho y estar facultado" en el estudio de la "Estática jurídica": Teoría pura del Derecho, editorial Porrúa, México (6. ${ }^{\text {a re- }}$ impresión). Traducción de Roberto J. Vernengo, pp. 138-150. Igualmente señala que "la captación de la esencia del derecho subjetivo (en el sentido de derecho con el que un sujeto cuenta) se hace difícil por el hecho de que con esas palabras ('derecho subjetivo') se designan circunstancias muy diferentes entre sí. A una de ellas se refiere el enunciado de que el in- dividuo tiene derecho a comportarse, él mismo, de determinada manera" (cursiva de la autora). Por su parte, A. E. Pérez Luño señala que el derecho objetivo y el derecho subjetivo aparecen como "dos especificaciones de una misma realidad: el derecho (...). Mientras el derecho objetivo aparece como la norma que permite o prohibe, el derecho subjetivo viene a significar el permiso o facultad que se deriva de la norma. El derecho subjetivo es una función del derecho objetivo, (...) supone lógicamente la existencia de la norma que imprime a la conducta facultada el sello de licitud" (cursiva de la autora). Teoría del Derecho. Una concepción de la experiencia jurídica, op. cit., pp. 50 y 51.

4 J. Habermas: Facticidad y validez, Trotta, Madrid, 1998, p. 200. Traducción de Manuel Jiménez Redondo.

5 N. Bobbio señala también que la vinculación que existe entre Estado y poder se proyecta en la forma que "adoptan los juristas para definir el derecho subjetivo: que un sujeto tenga un derecho subjetivo quiere decir que el ordenamiento jurídico le atribuye el poder de obtener ciertos efectos". Estado, gobierno y sociedad. Por una teoría general de la política, Fondo de Cultura Económica, México, 6. reimpresión, 1998, p. 98. Traducción de Jose F. Fernández Santillán (cursiva de la autora).

6 Para un estudio detallado del buen gobierno desde la perspectiva del deber ver el amplio trabajo de Ponde Solé, J.: Deber de buena administración y derecho al procedimiento debido. Las bases constitucionales de procedimiento administrativo $y$ del ejercicio de la discrecionalidad, editorial Lex Nova, Valladolid, 2001. Igualmente puede consultarse Rodríguez Arana, J.: El buen gobierno y la buena administración de las instituciones públicas, editorial Aranzadi, Pamplona, 2006.

7 http://www.boe.es/aeboe/consultas/ bases_datos/doc.php?coleccion=iberl exctid=2007/07788.

8 http://www.europarl.europa.eu/charter/pdf/text_es.pdf.

9 Tornos, J.: El derecho a una buena administración, Sindicatura de Greuges de Barcelona. Se trata de un informe encargado a este catedrático de Derecho Administrativo de la Universidad de Barcelona y publicado en noviembre de 2007: http://www.ben. es/sindicadegreuges/pdf/Informe $\% 20$ Buena\%20Administracion-castellano.pdf, pp. 14, 15 y 39. Consulta en línea 16 de julio de 2008.

10 Rodríguez Arana, J.: "El derecho fundamental al buen gobierno y a la buena administración de instituciones públicas", en http://www.ciberjure.com.pe/index.php?option=com_co ntent\&ttask=view\&tid $=2232$ ttlemid $=$ 9, consulta en línea el 23 de enero de 2009.

11 Nieto, A.: El desgobierno de lo público, Ariel, Barcelona, 2008. Ver también del mismo autor La "nueva" organización del desgobierno, Ariel, Barcelona, 1996.

12 M. Villoria da cuenta de diversas posiciones doctrinales en relación con lo que sea un buen gobierno: "Sería aquel que puede simultáneamente mantener la legitimidad moral y democrática y promover el desarrollo socioeconómico (Alcántara, 1995). 0 (...) aquel que, desde la fidelidad y el respeto a la normativa constitucional (...) ejecuta de forma eficaz, eficiente y responsable su programa (Camps, 1997), ejecución que sólo podrá ser alterada para beneficio colectivo y por cambio en las circunstancias debidamente explicadas. (...) Si se dan 
las adecuadas condiciones, el buen gobierno es fruto de la democracia, de la pluralidad de valores asociada a ella y de la racionalidad y razonabilidad de los seres humanos". Ética y corrupción: Curso de ética administrativa, Tecnos, Madrid, 2000, p. 72.

13 Tornos, J.: El derecho a una buena administración. http://www.bcn.es/ sindicadegreuges/pdf/Informe $\% 20$ Buena\%20Administracion-castellano.pdf, op. cit., pp. 28, 32 y 33.

14 Spitz, J. F.: Voz "Estado de naturaleza y Contrato Social", en Raynaud, P. y Rials, S. (eds.): Diccionario Akal de FiIosofía Política, Ediciones Akal, 2001, p. 265 (1. a columna).

15 A. Ruiz Miguel refiere también cómo el "estado de naturaleza es una situación considerada histórica y real para algunos filósofos, pero meramente supuesta o hipotética por otros". "Democracia constitucional", en Arteta, A.: El saber del ciudadano. Las nociones capitales de la democracia. Alianza Editorial, Madrid, 2008, pp. 235-261, en concreto p. 242.

16 Hobbes, T.: "Leviatán o La materia, forma y poder de una república eclesiástica y civil", en Hobbes, T., Del Ciudadano y Leviatán, Tecnos, Madrid, 5. edición, 1999, reimpresión 2001, pp. 43-210, en concreto, pp. 126, 127 y 128. Estudio preliminar y antología de Enrique Tierno Galván. Traducción de Enrique Tierno Galván y M. Sánchez Sarto. Un libro valioso para ahondar en la obra de Hobbes es el de R. Peters: Hobbes, Penguin Books, Reino Unido, 1956.

Para I. Kant, el estado de naturaleza es "un estado de guerra", si bien este estado bélico no tiene que ser una situación de hostilidades permanentes y abiertas sino que en él hay una "constante amenaza" a la paz que sí habría en un Estado de Derecho. Sobre la paz perpetua, Tecnos, Madrid, 2005, p. 14. Traducción de Joaquín Abellán. I. Kant establece también que "(...) antes de que se establezca un estado legal público, los hombres, pueblos y Estados aislados nunca pueden estar seguros unos de otros frente a la violencia y hacer cada uno lo que le parece justo y bueno por su propio derecho (...)". La Metafísica de las Costumbres, Tecnos, Madrid, 1999 (3. edición), 306, p. 141. Estudio preliminar de Adela Cortina Orts. Traducción y notas de Adela Cortina Orts y Jesús Conill Sancho.

17 Rousseau, J. J.: El contrato social o Principios de derecho político, Tecnos,

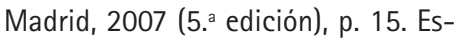
tudio preliminar y traducción de María José Villaverde (cursiva de la autora).

18 Kant, I.: La Metafísica de las Costumbres, op. cit., p. 136.

19 Aristóteles: Política, Alianza Editorial, Madrid, 2007 (6. a reimpresión) $^{2}$ [1253 a)], pp. 47 y 48. Traducción y notas de Carlos García Gual y Aurelio Pérez Jiménez. Es necesario señalar la gran diferencia que hay entre las diversas traducciones de la obra de Aristóteles. Así, en la versión citada se utiliza el término "ciudad" para referirse a lo que en otra traducción de Patricio de Azcárate (Obras de Aristóteles, Madrid, 1874, tomo 3, pp. 17-31. Existe una versión en <http://www.filosofia. org/cla/ari/azc03.htm>) se emplea "Estado". Las palabras "asociación" y "comunidad" aparecen utilizadas de forma indistinta en la traducción de García Gual y se refiere a la comunidad cívica en los mismos términos que lo hace Azcárate para nombrar la "asociación política".

20 Calhoun, J. C.: Disquisición sobre el gobierno, Tecnos, Madrid, 1996, p. 6. Estudio Preliminar de Pablo Lucas Verdú. Traducción y notas de María de la Concepción Lucas Murillo de la Cueva.

21 Hay incluso quien afirma que "no se ha observado nunca en ninguna era o país, en ningún otro estado, que el hombre no sea social. Sin duda no podría existir de otro modo". Calhoun, J. C.: Disquisición sobre el gobierno, op. cit., pp. 5 y 6.

22 Beauvais, A. S.: Manual Clásico de Filosofía, tomo II, imprenta de Don Ramón Verges, Madrid, 1845 (2. ${ }^{\text {a edi- }}$ ción corregida y aumentada), pp. 453 454,455 y nota 15 de las pp. 454 y 455 del propio autor. Traducido, arreglado y adicionado por José López de Uribe y Osma.

23 Spitz, J. F: Voz "Estado de naturaleza y Contrato Social", en Raynaud, P. y Rials, S. (eds.): Diccionario Akal de Filosofía Política, op. cit., pp. 262 (2. ${ }^{a}$ columna) y 263 (1. ${ }^{\text {a }}$ columna). En la p. 263 (2. columna) se aclara que "la realidad histórica del estado natural cuenta menos que su función lógica de desvelamiento de los rasgos cruciales de la naturaleza humana. Alli donde se afirma esta realidad histórica, no es tanto para establecer un punto de historia como para mostrar que los hombres pueden conducirse según los principios de su sola naturaleza: la historización del concepto responde así al imperativo de probar la posibilidad de deshacerse de las contingencias de la costumbre y las iniciativas contingentes, para gobernarse sólo por las leyes que se deducen de nuestras facultades natas y de nuestras necesidades fundamentales" (subrayado de la autora).

24 Spitz, J. F: Voz "Estado de naturaleza y Contrato Social", en Raynaud, P. y Rials, S. (eds.): Diccionario Akal de Filosofía Política, op. cit., p. 263 (1. ${ }^{\text {a columna). }}$ 
25 A. Ruiz Miguel da cuenta de ello cuando señala que "desde los mandamientos de Moisés al Código de Hammurabi, desde las leyes de Licurgo o de Solón hasta las XII Tablas romanas, desde los Diez Mandamientos a la Torá hebrea o a la Sahria islámica, desde el Derecho de Graciano a las Partidas de Alfonso $X$, el lenguaje legal ha tendido a declinarse mediante obligaciones y prohibiciones antes que de derechos y libertades". Además señala que "es muy indicativo que ni siquiera el Derecho romano contara con un término que significara lo que nosotros expresamos mediante la palabra 'derecho'". Democracia constitucional, op. cit., p. 241.

26 N. Bobbio señala que "en toda la tradición ius-naturalista el estado de naturaleza que es anterior al estado civil es representado indiferentemente como una condición de aislamiento puramente hipotética o como una situación en la cual habrian vivido los pueblos primitivos y viven hasta hoy los salvajes; en ambos casos, con la condición en la que los hombres viven cuando todavía no ha surgido el Estado llamado no por casualidad, en antítesis al estado de naturaleza". Estado, gobierno y sociedad. Por una teoría general de la política, op. cit., p. 98.

27 Kant, I.: "Contestación a la pregunta: ¿Qué es la llustración", en Rodríguez Aramayo, R. (ed.), ¿Qué es la Ilustración? Y otros escritos de ética, política y filosofía de la historia, Alianza Editorial, Madrid, 2007 (primera reimpresión), pp. 81-93, en concreto pp. 83, 85 y 93.

28 Humboldt, W. V.: Los límites de la acción del Estado, Tecnos, Madrid, 1988, pp. 14-20 sobre "el fin último del hombre". La cita en concreto es de la p. 20.
29 Rousseau, J. J.: El contrato social o Principios de derecho político, op. cit., pp. 4 y 5.

30 E. Rey Cantor da cuenta de las diferentes teorías políticas de la formación del Estado a lo largo de la historia, siendo las más relevantes desde el punto de vista de este trabajo las Ilamadas teorías contractualistas, entre las que se encontrarían las de Aristóteles, Thomas Hobbes, John Locke o Jean-Jacques Rousseau. Teorías política clásicas de la formación del Estado, editorial Temis, Colombia, 1996, pp. 63-117.

31 Prieto Sanchis, L.: Justicia Constitucional y derechos fundamentales, editorial Trotta, Madrid, 2003, p. 148.

32 Ver la referencia a Platón y a Aristóteles que hace N. Bobbio: Estado, gobierno y sociedad. Por una teoría general de la política, op. cit., pp. 130 y 131.

33 Calhoun, J. C.: Disquisición sobre el gobierno, op. cit., pp. 6 y 8.

34 Ruiz Miguel, A.: "Democracia constitucional", en Arteta, A., El saber del ciudadano. Las nociones capitales de la democracia, op. cit., p. 242.

35 Referido por N. Bobbio al referirse al texto de Marx y Engels, de 1845, La sagrada familia, p. 130. Estado, gobierno y sociedad. Por una teoría general de la política, op. cit., p. 47.

$36 \mathrm{~N}$. Bobbio da cuenta de la distinción seguida en la literatura alemana entre sociedad civil sin poder central y sociedad civil con poder central, que sería la que correspondiera al término Estado. Estado, gobierno y sociedad. Por una teoría general de la política, op. cit., p. 39.

37 Bobbio, N.: Estado, gobierno y sociedad. Por una teoría general de la política, op. cit., pp. 41 y 42.

38 Señala N. Bobbio que "la sociedad civil es el lugar donde surgen y se de- sarrollan los conflictos económicos, sociales, ideológicos, religiosos, que las instituciones estatales tienen la misión de resolver mediándolos, previéndolos o reprimiéndolos". Estado, gobierno y sociedad. Por una teoría general de la politica, op. cit., p. 43.

39 Sin embargo, siguiendo a J. Sprute, "Kant no podía legitimar el poder estatal remitiéndose a la incapacidad de los hombres -supuestamente comprobada por la experiencia- para una convivencia sin poder político porque los hechos empíricos no tiene fuerza demostrativa para las proposiciones de indole estrictamente científica (...). La necesidad del estado es para Kant un conocimiento a priori del último tipo, es decir un conocimiento que se consigue independientemente de la experiencia concreta de las situaciones vividas. Tan sólo desde esta teoría del Estado, que depende del presupuesto kantiano de la libertad externa como derecho innato de los hombres, es posible hacer transparente la teoría de Kant". Filosofía politica de Kant, Tecnos, Madrid, 2008, pp. 43 y 44. Traducción de C. A. Lemke Duque. Subrayado de la autora.

40 Habermas, J.: Facticidad y validez, op. cit., p. 201.

41 No en vano, N. Bobbio, intentando aportar argumentos a favor o en contra de la continuidad del concepto de Estado, señala en su favor que "también en el alto medievo no decae la idea de regnum y del imperium, o sea, de un poder que es el único autorizado para ejercer, en última instancia, la fuerza, porque tiene como fin supremo de su preeminencia el mantenimiento de la paz y el ejercicio de la justicia (...)". Estado, gobierno y sociedad. Por una teoría general de la política, op. cit., p. 96. 
42 Bobbio citando a Ferguson en Estado, gobierno y sociedad. Por una teoría general de la política, op. cit., pp. 89 y 98.

43 Bobbio, N.: Estado, gobierno y sociedad. Por una teoría general de la política, op. cit., p. 67.

44 Rousseau, J. J.: El contrato social, op. cit., p. 22.

45 Pérez Luño, A. E.: Derechos humanos, Estado de Derecho y Constitución, Tecnos, Madrid, 2005 (9. a edición), p. 222.

46 Kant. I.: Teoría y Práctica, Tecnos, Madrid, 2005, p. 25. Estudio preliminar de Roberto Rodríguez Aramayo. Traducción de Juan Miguel Palacios, M. Francisco Pérez López y Roberto Rodríguez Aramayo.

47 Humbold, W. V.: Los límites de la acción del Estado, op. cit., p. 21.

48 Humbold, W. V.: Los límites de la acción del Estado, op. cit., pp. 14-20.

49 Sprute, J.: Filosofía política de Kant, op. cit., pp. 50 y 51.

50 Kant, I.: La Metafísica de las Costumbres, op. cit., 230, p. 39.

51 Para una exposición más detallada de la relación entre el Estado, la política y el poder ver, Bobbio, N.: Estado, gobierno y sociedad, op. cit., pp. 101-127.

52 Señala A. E. Pérez Luño que "la propia noción de Estado de Derecho representó (...) la búsqueda de un 'ideal institucional' o de una 'realidad espiritual', dirigida a proteger al ciudadano con su libertad, sus valores, así como sus derechos innatos y adquiridos frente al peligro de eventuales abusos por parte de los detentadores del poder político". Derechos humanos, Estado de Derecho y Constitución, Tecnos, Madrid, 2005

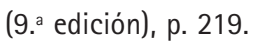

53 A. Troncoso Reigada señala igualmente que "un Estado de Derecho no es un Estado con derecho". Junto a las condiciones que hemos apuntado, él señala "la vigencia del principio democrático" y matiza que "el concepto de Estado de Derecho, cuando es acuñado por Jellinek, Mayer, Mohl o Stein, es previo al Estado democrático de derecho y encuentra su origen dogmático en Kant, en la idea de un Estado donde impera la razón". "Dogmática administrativa y derecho constitucional: el caso del servicio público", en Revista Española de Derecho Constitucional, año 19, n. 47. septiembre-diciembre 1999, pp. 87164 , en concreto p. 89, nota 6 . Se puede consultar también en http:// www.cepc.es/rap/Publicaciones/Revistas/6/REDC_057_085.pdf. En línea el 19 de julio de 2008.

Sin embargo, P. Dermizaky Peredo refiere cómo según Carl Schmitt, sólo los derechos fundamentales y la división de poderes son la sustancia del Estado de Derecho. "Estado de Derecho y buen gobierno", en lus et praxis, año/ volumen 6, n. ${ }^{\circ}$, Universidad de Talca, Chile, pp. 145-151, en concreto p. 145. Consultar en http://redalyc.uaemex.mx/ redalyc/pdf/197/19760207.pdf. En línea el 19 de julio de 2008.

54 Bobbio, N.: Estado, gobierno y sociedad, op. cit., pp. 125 y 126.

55 Bobbio, N.: Estado, gobierno y sociedad, op. cit., p. 116.

56 Prueba de ello es que "el concepto de servicio público nace cuando el Estado deja de limitar su actuación a la preservación de la libertad y a la garantía de los derechos individuales (...) y se convierte en protagonista directo del crecimiento económico y del progreso social". Troncoso Reigada, A.: "Dogmática administrativa y derecho constitucional: el caso del servicio público", op. cit., p. 98.
57 Tornos, J.: El derecho a una buena administración, op. cit., p. 29.

58 Ruiz Miguel, A.: "Democracia constitucional", op. cit., pp. 250 y 251.

59 Troncoso Reigada, A.: "Dogmática administrativa y derecho constitucional: el caso del servicio público", op. cit., p. 148.

60 Sobre el particular, ver Troncoso Reigada, A.: "Dogmática administrativa y derecho constitucional: el caso del servicio público", op. cit., pp. 151 y 155.

61 Troncoso Reigada, A.: "Dogmática administrativa y derecho constitucional: el caso del servicio público", op. cit., p. 153. L. Prieto Sanchís, remitiéndose a su vez a Ferrajoli, aclara que "no cabe duda de que el Estado Constitucional representa una fórmula del Estado de Derecho, acaso su más cabal realización, pues si la esencia de Estado de Derecho es el sometimiento del poder al Derecho, sólo cuando existe una verdadera Constitución ese sometimiento comprende también al legislativo; de ahí que quepa hablar del constitucionalismo como un perfeccionamiento del Estado de Derecho". Justicia Constitucional y derechos fundamentales, op. cit., p. 113.

62 Prieto Sanchís, L.: Constitucionalismo y positivismo, Distribuciones Fontamara, México, 1999 (2. edición), pp. 15, 16 y 17.

63 Tornos, J.: El derecho a una buena administración, op. cit., pp. 31 y 32.

64 Sin embargo esta afirmación no puede llevarnos a concluir que el Constitucionalismo sintetice la reconciliación entre el Derecho y la Moral y a partir de él sean dos órdenes normativos vinculados.

65 Sobre el tema del interés general, ver Terol Becerra, M. J.: "El interés general, su importancia en el esquema de 
distribución de competencias entre el Estado y las Comunidades Autónomas", en Revista de Estudios Políticos (Nueva Época), núms. 46-47, juliooctubre de 1985, pp. 433-453. Puede también consultarse en <http:// www.cepc.es/rap/Publicaciones/Revistas/3/REPNE_046-047_424.pdf>;
Parejo Alfonso, L.: "El interés público como criterio de control de la actividad administrativa", en http://www. iadb.org/etica/Documentos/par_inter.doc.

66 Shetty, S.: "Declaración y objetivos de desarrollo del milenio: Oportunidades para los derechos humanos", en Sur. Revista Internacional de Derechos Humanos, año 2, n. ${ }^{\circ}$ 2, 2005, pp. 6-21. Traducción de Claudia Otero, p. 10. Ver también en <http:// www.surjournal.org/esp/conteudos/ artigos2/esp/artigo_shetty.htm $>$. Consulta en línea el 26 de enero de 2009. 